\title{
Work in Progress - Improving Learning Using Industry Supported Project in Power Electronics Course
}

\author{
Taufik Taufik \\ Electrical Engineering Department, California Polytechnic State University \\ San Luis Obispo, CA 93407 taufik@calpoly.edu
}

\begin{abstract}
This paper presents an approach that has recently been developed and initiated in teaching undergraduate power electronics course to enhance the learning by exposing students to the most recent state of power electronics technology and applications. The approach involves a hardware project that is supported by industry that is at the forefront of power electronics technology, applications, and devices. The hardware project will be detailed in this paper along with the grading and assessment methods. Difficulties encountered will also be presented.
\end{abstract}

Index Terms - Electrical Engineering courses, Power Electronics courses.

\section{INTRODUCTION}

Power electronics is an engineering discipline that deals with the conversion of electrical power from one form to another. Power electronics has become increasingly important nowadays where billions of kilo-watts of electric power are being re-processed every day to provide the kind of power needed by loads [1]. Due to the rapid growth in power electronics technology, there has been an increasing number of power electronics companies who come and visit on-campus career fair at Cal Poly to recruit electrical engineering (EE) students with power electronics background. This in turn has triggered a great interest among our EE students to the field of power electronics as indicated by the steady increase in the number of students enrolled in power electronic courses [2].

To better prepare our EE students and to better align with industry needs, the three existing power electronic courses (beginning, intermediate and advanced) at Cal Poly have recently been redesigned. Besides updating the course contents, new lab experiments involving both concepts and modern applications have also been developed in the lab portion of the courses. Equally important is the newly developed hardware projects that have been designed to improve the learning by exposing students to real-world circuit designs. These hardware projects were designed in such a way that their level of difficulty and practicality increases with the progression of the three power electronic courses. This paper focuses on the newly developed hardware project for the introductory power electronic course. This hardware project is unique in a way that it serves as the first exposure to practical issues in power electronics and it is mostly supported by industry.

\section{Hardware Project BaCkground}

Prior to developing the hardware project for the introductory course in power electronics, discussions with several power semiconductor companies took place to receive input on their expectations and needs of our EE graduates. Responses from them include for examples circuit layout, real world component selections, soldering skills, surface mount components, magnetic design/calculations, and performance testing of dc-dc converter. Unfortunately, due to time constraints, it is not viable to cover most of these topics in all of the existing power courses. The next logical route is therefore to try to present these topics in the lab component of the courses. However, this was found to be difficult as well since the new lab experiments had just been developed and thus no space was left to introduce new experiments. To overcome this problem, it was then decided that these suggested topics should be spread around the three existing power electronic courses rather than trying to hit all these topics in the introductory course. For example, the circuit layout will be tackled in the advanced course in the form of a hardware project. Performance testing of dc-dc converter will be covered both in class and in the lab portion of the introduction course. Real world component selections will be addressed in the intermediate course also in a form of a hardware project. As for the magnetic design, since it is a major topic by itself, a new introductory course in magnetic design is currently being developed. Finally, surface mount components and soldering skills will both be covered in the introductory course as part of a hardware project.

One power semiconductor company that was visited during the initial stage of developing the hardware project for the introductory course was Linear Technology in Milpitas, California. Discussions during this visit resulted in a plan for a hardware project that was not design-driven, but rather addressed the commonly observed issues of fresh EE graduates lacking knowledge of surface mount components and soldering skills. In addition, the hardware project would also require students to perform several standard dc-dc converter performance tests. To help carry out this plan, Linear Technology generously offered to support the hardware 
project by providing most of the surface mount components and the circuit board required to complete the project.

\section{The Hardware Project}

The hardware project for the introductory course was first assigned in Fall 2006 and then again in Winter 2007. A group of 2 to 3 people is required to perform the project and the project is worth $15 \%$ of the overall grade. During the $10^{\text {th }}$ week of the quarter, each group has to demo their hardware project and is being graded based on criteria as depicted below:

Objective: Build a Boost converter using LT1615 switching regulator from Linear Technology.

The converter must meet the following specifications:

1. Nominal Input Voltage $=3.3 \mathrm{~V}$

2. Nominal Output Voltage $=20 \mathrm{~V}$

3. Maximum Output Current $=12 \mathrm{~mA}$

4. Peak to peak output voltage ripple at full load of $<1 \%$

5. Load regulation at nominal input $10 \%$ to $90 \%$ load $\leq 5 \%$

6. Line regulation at full load while input is changed from $2.5 \mathrm{~V}$ to $4.2 \mathrm{~V} \leq 1 \%$

7. Efficiency at full load $\geq 75 \%$. At the time of the demo, please provide Efficiency Plot with data taken from $10 \%$ to $100 \%$ of load in steps of $10 \%$.

The grade for this project will be based on:

- How well the converter meets above specifications

- Neatness/aesthetic of the converter (wiring, component placements, layouts)

Upon completion of your demo, you must create a webpage containing:

- Title of the Project and Your names

- A picture of your Boost converter

- A picture of the efficiency plot of your converter

Figure 1 shows a picture of a completed circuit board from the hardware project.

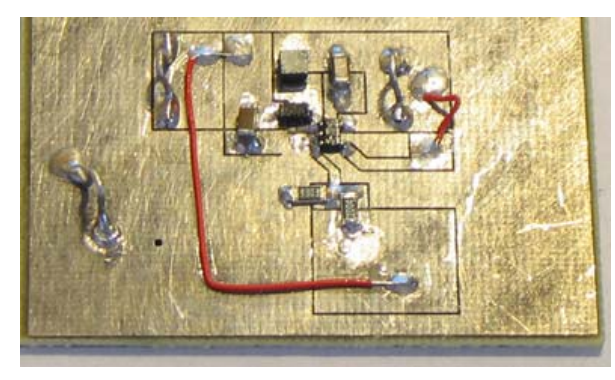

FIGURE 1

Completed circuit board

\section{ASSESSMENT}

Although the hardware project has been implemented for only two quarters, preliminary assessment was developed and data were collected. Presently, the assessment takes the form of a total of seven short yes or no questions as shown in table 1.

TABLE 1

Survey questions with responses

\begin{tabular}{|l|c|c|}
\hline \multicolumn{1}{|c|}{ Survey Questions } & Yes & No \\
\hline $\begin{array}{l}\text { Before this project, have you worked on } \\
\text { surface mount components (selecting, buying, } \\
\text { or soldering)? }\end{array}$ & $28.95 \%$ & $71.05 \%$ \\
\hline $\begin{array}{l}\text { Before this project, were you aware of surface } \\
\text { mount inductor? }\end{array}$ & $39.47 \%$ & $60.53 \%$ \\
\hline $\begin{array}{l}\text { Before this project, were you aware of surface } \\
\text { mount power electronic components? }\end{array}$ & $50 \%$ & $50 \%$ \\
\hline $\begin{array}{l}\text { Has the project increased your awareness of } \\
\text { surface mount power electronic components? }\end{array}$ & $97.37 \%$ & $2.63 \%$ \\
\hline $\begin{array}{l}\text { Has the project increased your skill in working } \\
\text { with surface mount components? }\end{array}$ & $97.37 \%$ & $2.63 \%$ \\
\hline $\begin{array}{l}\text { Has the project helped you in learning dc-dc } \\
\text { converter in general? }\end{array}$ & $97.37 \%$ & $2.63 \%$ \\
\hline $\begin{array}{l}\text { Has the project helped you in learning dc-dc } \\
\text { converter performance testing such as line and } \\
\text { load regulations, efficiency, peak to peak } \\
\text { output voltage ripple? }\end{array}$ & $89.47 \%$ & $10.53 \%$ \\
\hline
\end{tabular}

\section{CONCLUSIONS AND FURTHER WORK}

In this paper, a new hardware project sponsored by industry and assigned to an introductory power electronic course has been presented. The project is aimed to expose students with practical issues in power electronics design which in turn will enhance students learning of power electronics as evidenced in the preliminary results of the survey. Difficulties encountered from student's point of view include the steep learning curve on soldering and handling surface mount components which may be time consuming and frustrating. In addition, due to time constraints the project has minimal exposure on the component selection aspect of the design. From the instructor's perspective, a lot of time has to be allocated for to help students troubleshoot problems and for the hardware demos. Much work still needs to be done in terms of improving the survey questions to assess the level of skills of students before and after the hardware project. Linear Technology as the industry expert and counterpart on this effort will be involved in the assessment process. At present time all components but the capacitors are supplied by Linear Technology. Therefore, future sponsor that will supply the capacitors will be sought.

\section{REFERENCES}

[1]. P. Thollot, "Power Electronics Today", Proceedings of the 1990 IEEE Colloquium in South America, 1990, Pages 184-187.

[2]. Taufik, "Power Electronics Courses That Work", Proceedings of 2006 Frontier in Education Conference, San Diego, Oct 2006. 